\title{
Emerging Technologies in Agriculture
}

\author{
Matthew N. O. Sadiku1*, Tolulope J. Ashaolu' ${ }^{2}$, and Sarhan M. Musa1
}

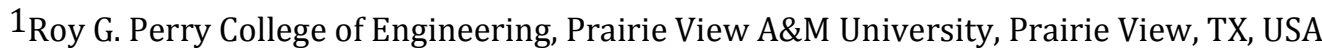 \\ ${ }^{2}$ College of Food Science, Southwest University, Tiansheng Road Beibei District, Chongqing, 400715, P.R. China \\ E-mail: sadiku@ieee.org; ashaolut@gmail.com; smmusa@pvamu.edu \\ *Corresponding author details: Professor Matthew N. O. Sadiku, sadiku@ieee.org
}

\begin{abstract}
Technology has been a major contributing factor in how we live, communicate, travel, and interact in the modern society. The great boom of technology is having huge impact on all industries, especially agriculture industry. Agriculture is the backbone of most developing economies. Today, agriculture is going through massive transformation due to digitization. New technologies such as robots, drones, and machine learning are supposed to help farmers improve efficiency and maximize yield. Emerging technologies have already proven to be a key driver in the future sustainability and profitability of agriculture. This paper provides an introduction to emerging technologies in agriculture.
\end{abstract}

Keywords: technology; emerging technologies; agriculture

\section{INTRODUCTION}

Agriculture has been the key sector for the economic development for most nations. It ranges from small firms, to large firms, to huge multi-national businesses. Agriculture is more than farming and ranching, which are just its production sector. It is also the business (agrobusiness) that transforms agricultural commodities into consumer products. Moving the commodities to consumers involves food processing, packaging, transportation, retail, preparation, and consumption at home. Agriculture has gone through some evolutions. Recently, mechanization revolutionized farming with machinery and replaced horses with tractors. Today, technology has been adopted in an increasing rate to the extent that technology has become an indispensable necessity for every farmer, especially in developed nations. There is not enough land worldwide to support today's world population using yesterday's technology.

Technology is impacting every aspect of our modern lives, and agriculture is no exception. In simple terms, technology may be regarded as the set of skills that allow us to build objects and machines to satisfy our needs. Technology in agriculture, also known as AgTech, has rapidly changed the industry in recent years. Technologies are helping farmers improve efficiency and maximize yield. Some major technologies that are commonly utilized by farms include: harvest automation, autonomous tractors, seeding and weeding, and drones. Recent trends have proven that technology is revolutionizing the world of livestock management, which runs the business of poultry farms, dairy farms, cattle ranches, or other livestock-related agribusinesses. Livestock provides much needed renewable, natural resources that we need daily.

The emerging technologies can literally transform the agricultural landscape in the years to come. Emerging technologies ranging from robotics to machine language have completely transformed modern agriculture, both on a small scale and large scale. They will take agriculture to new heights.
By introducing these game-changing technologies, we can explore new ways to grow and deliver food to the masses.

\section{EMERGING TECHNOLOGIES}

Farmers are facing pressures including the need to produce more with less in order to feed an expanding global population, minimize the threat to environment, cope with a rising global temperature, survive with water and energy crunches, and satisfy the new food preferences of a rising generation of digital-natives, tech-savvy customers. Emerging technologies can help address these challenges. Here we consider some emerging technologies in agriculture [1-5].

\section{Sensor Technology:}

This is the most popular technology. Farms are finding it affordable to place sensors strategically throughout their land in order to ripe many benefits. Sensors along with image recognition technologies are allowing farmers to view their crops from anywhere in the world. Sensors help agriculture by enabling real-time traceability. They would enable a real time understanding of current farm, forest or water condition. They are helping to monitor and manage livestock and crop production. They also help the farm be more environmentally friendly by conserving water, limiting erosion, and reducing fertilizer levels in local rivers and lakes. After crops are harvested, RFID sensors can be used to track food products from the field to the store.

\section{Vertical Farming:}

Vertical farming has come to urban areas. Indoor vertical farming is the practice of growing produce stacked one above another in a closed and controlled environment. In place of natural sunlight, artificial lights are used in growing. Vertical farming is not only scientifically viable but will be financially viable within the decade. It is basically a component of urban agriculture that produces food in vertically stacked layers. It is not limited to just urban environments. It can be used in all areas to make better use of available land. Vertical farming can increase crop yields, overcome limited land area, and reduce farming's impact on the environment. Due to the ability to 
grow year-round, this kind of indoor farms are expanding across the US. Figure 1 illustrates a typical vertical farming [6].

\section{Organic Farming:}

This also known as ecological agriculture- Organic farming is eco-friendly in nature and do not harm the environment. It is considered as a better alternative to chemical based farming, which uses chemicals. Organic farming or agriculture is a production system that largely avoids the use of chemical fertilizers and pesticides. It is a system that sustains the health of soils, ecosystems, and people. It generally prohibits products of genetic engineering and animal cloning, synthetic pesticides, and synthetic fertilizers. It occupies a unique position in the world's agricultural systems. The main goal of organic farming is to develop enterprises that are sustainable and harmonious with the environment. Organic farming promotes the use of crop rotations, crop diversity, use of crop residues, animal manures, legumes, green manures, off farm organic wastes, biofertilizers, and mechanical cultivation. It works in harmony with nature [7]

\section{Smart Farming:}

This is the future of agriculture. Smart farming is an application of IoT solutions. They involve using predictive analytics to make smarter decisions in farming by collecting real-time data on weather, soil, crop maturity, equipment, and labor costs. Smart farming refers to the adoption of information and communications technologies (ICT) to enhance and automate agricultural processes and operations. Smart farming technologies cover all these aspects of precision agriculture. It applies to small (family farming) and complex family as well as organic farming. Smart farming is replacing inefficient, inconsistent, and unreliable traditional farming techniques. It is posed to increase the competence of certain farming activities. It uses wireless sensor networks for noting the soil properties and environmental factors continuously. It employs smart irrigator system to spray the necessary nutrients according to the requirements of the crops [8].

\section{Precision Agriculture Technology:}

Precision agriculture (or precision farming) is about providing more accurate farming techniques for planting and growing crops. It is the use of information and communication technology (ICT) along with best agricultural practices. It may boost agricultural production while reducing harmful impact on the environment. It can make a big difference to food production facing the challenge of a rising world population. The practice of precision agriculture is enabled by several technologies such as drones IoT, GPS guidance, sensors, robotics, autonomous vehicles, and telematics [9].

\section{Robots:}

Agricultural robots are also known as agbots. Robotics is the use of robots or automated machines in place of humans to perform physical tasks. Robots are employed by farmers to automate agricultural processes, such as harvesting, fruit picking, soil maintenance, weeding, planting, irrigation, spraying, weeding, etc. , which seemed to be too delicate for robotics in the past. Robots improve productivity and would result in higher yields. They also reduce the manpower. Figure 2 show the use of robots in agriculture [10]

\section{Drones:}

Drones are autonomous or remotely controlled multipurpose aerial vehicles driven by aerodynamic forces. They are devices which are capable of sustained flight and do not have a human on board. Drones are increasingly being used as innovative tools in agriculture. The only way farmers can get a bird's eye view of their fields is from a plane or a drone. Drones are being used for crop monitoring and spraying chemicals on crops, Drones can produce 3D imaging that can be used to predict soil quality. Sensors attached to drones can be used to monitor crop health, soil health, or detect weed data in crops. Ag-focused drone manufacturers include AgEagle, AeroVironment, and Sentera. Drones are now regulated by the FAA in the US. Figure 3 shows an agricultural drone [11].

\section{Automation Technology:}

This refers to any tool that can reduce operator workload. It combines the use of sensors, computers, feeding mechanisms, and robots. Robotics, removing the human from the operation, gets all the attention. Automation is the main focus of technological advances in agriculture, and it is already employed worldwide. GPS-guided tractors and planters are cost-effective technology where the driver basically monitors systems. The intelligent, autonomous tractor is poised to transform the agricultural industry due to its many applications. Automation technology can make the farming safer and more productive. Most field crops are mechanized throughout their production, handling and storage operations. No matter how automated the farm is, labor is inevitable in agriculture. An example of automation in farming is depicted in Figure 4 [12]

\section{Machine learning:}

Machine learning (ML) is an emerging field of artificial intelligence (AI) which can be applied to the agriculture sector. It refers to the automated detection of meaningful patterns in a given data. Modern agriculture seeks ways to conserve water, use nutrients and energy more efficiently, and adapt to climate change. Machine learning in agriculture allows for more accurate disease diagnosis and crop disease prediction. AI and ML algorithms are helping farmers sift through data to come to powerful insights to help them increase efficiency, productivity and yields. ML algorithms can also be used within the manufacturing aspect of agriculture [13].

\section{Big Data}

We live in a big data age where huge volumes of information are generated, collected, and managed to add value to our daily lives. Today, farmers are deploying enormous amounts of data generated by interconnected devices to get an overall understanding of their farms. If tractors transformed farming in the middle ages, the evolution of big data is revolutionizing the agriculture industry in our time. The big data revolution is modernizing the farming industry at a pace we have never witnessed [14]. Big data will change how farmers manage their work. Rather than relying on educated guesses, farmers can now rely on big data to make better, more informed decisions.

\section{Blockchain:}

Blockchain consists of a shared or distributed database used to maintain a growing list of transactions, called blocks. Blockchain technology, often called the chain of trust, can support transactional applications and streamline business processes by establishing trust, accountability, and transparency. Although blockchain was first largely applied in financial industry as the technology that allowed Bitcoin to operate, it has applications for many industries including agriculture, healthcare, insurance, pharmacy, and manufacturing [15]. Blockchain's capability of tracking ownership records and tamper-resistance can be used to address issues such as food fraud, safety recalls, supply chain inefficiency, and food traceability. The record of a food item's journey, from farm to table, can be monitored in real-time. Blockchain 
enables verified transactions and creates a marketplace with immense transparency.

\section{RFID technology:}

RFID stands for Radio Frequency Identification. It refers to technologies that use radio waves to identify objects, animals, or people. Due to its low energy consumption and adaptability to different environments, RFID has found applications in many fields. RFID uses radio frequency waves to identity and track tags connected to objects. RFID technology is used to track all sorts of items. RFID tags and RFID readers can be used to manage agricultural inventories. For example. A bag of rice can have a barcode that can be scanned with your smartphone to retrieve information about the rice.

\section{Internet of Things:}

The concept of the Internet of things (IoT) is to connect anything, anytime, and anywhere through Internet. It is the network of devices that are connected to each other and allow exchange of the data among themselves. IoT is being deployed across the globe to solve some of the most pressing issues. The IoT is disrupting the agriculture industry in a positive manner. With the help of the Internet of things, farmers can control the activities of the devices due to the connectivity.

Other emerging technologies include biotechnology, artificial intelligence, GPS, GIS, RFID, 3D printing, genomics, satellites greenhouses, regenerative agriculture, conservation technology, aquaponics, carbon farming, microbial farming, hyper precision, remote monitoring systems, nuclear magnetic resonance, and nanotechnology. These emerging technologies should be used judiciously to meet the growing demands and challenges of modern agriculture.

\section{BENEFITS}

Technology is playing a major role in developing the agricultural industry. With the emerging technologies, it is an exciting time to be a farmer. Microsoft, the software giant, is now going into farming. Its agricultural specialists are working to optimize the development of a broad spectrum of food crops.

The benefits of emerging technology in agriculture include [16-18]:

- Machines can be used for sowing the seeds and for the harvesting of crops, thereby reducing efforts of farmers

- Farmers can farm more land in one growing season than ever before

- Technology can increase production and reduce the production time.

- Technologies increase productivity and competition by allowing producers to increase output

- Technologies increase the price and demand of the products.

- Technology can help farmers access profitable markets, access finance, and access quality inputs

- Alert farmers to incoming storms or other dangerous weather conditions

- Decreased use of water, fertilizer, and pesticides makes food healthy and keeps food prices down

- Reduce the impact on the ecosystem

- Technology is the basis for sustainability

- Farming would be a more transparent activity

\section{CHALLEGES}

The industry is facing many challenges, such as rising costs of supplies, a shortage of labor, and changes in consumer preferences. Other challenges include [16-18].
- Modern agriculture has multiplied the negative impacts on the environment due to excessive use

- The climate is the main factor that is unpredictable which can hamper yield

- The cost of maintenance of the machines is high

- Due to lack of education, farmers are unable to run some machines properly

- Water diversions for agriculture are a major problem for many aquatic species

- $\quad$ Farmers need to be mindful of a complex, growing web of new government mandates and regulations

\section{CONCLUSION}

Agriculture plays a vital role in the social and economic development of most developing nations and is the main contributor to their economic growth and stability. Through the application of modern technologies, agriculture has undergone extensive changes during the past century. These technologies are producing new machinery and process techniques for the production, postharvest handling, and agrobusiness. They are also resulting in innovations in agriculture that make agriculture a sustainable, profitable, and competitive enterprise. The challenges posed by today's and tomorrow's global food demand will continue to push the agriculture industry towards technological innovations. Although new and emerging technologies promise to advance the plight of farmers (facing increasing pressures such as climate change, land scarcity, animal feed availability, price stresses, and soaring input costs), a number of economic, infrastructural, and regulatory obstacles hampers the choice of farmers to adopt new and emerging technologies.

Globalization has brought greater awareness of opportunities and alternatives for farmers to enhance their incomes. Progressive farmers are helping in diffusion of better agriculture technologies in their geographical areas. This makes the agriculture industry to continue to evolve as a dynamic and consumer-driven sector. More information about emerging technologies in agriculture can be found in the books in [19-26]

\section{REFERENCES}

[1] “7 Emerging agriculture technologies," January 2016,https://www.ayokasystems.com/news/emer ging-agriculture-technologies/

[2] M. Zappa, "15 Emerging agriculture technologies that will change the world," May 2014,

https://www.businessinsider.com/15-emergingagriculture-technologies-2014-4

[3] D. Newman, "Top six digital transformation trends in agriculture," May 2018,

https://www.forbes.com/sites/danielnewman/20

18/05/14/top-six-digital-transformation-trendsin-agriculture/\#3890b76aed2e

[4] J. Russo, "Top 5 trends in agriculture technology," March2013,

http://www.croplife.com/management/top-5trends-in-agriculture-technology

[5] L. Ku, "New agriculture technology in modern farming," https://www.plugandplaytechcenter.com/resourc es/new-agriculture-technology-modern-farming/

[6] "Six technology trends in farming this year," https://www.21stcentech.com/agriculture-newtechnologies-food-security-21st-century/

[7] M. N. O. Sadiku, S. M. Musa, and O. M. Musa, "Organic farming: A primer," World Journal of Engineering Research and Technology, vol. 5, no. 4, 2019, pp. 1-9.

[8] A. Walter et al., "Opinion: Smart farming is key to developing sustainable agriculture," Proceedings of the National Academy of Sciences of the U S A, vol. 114, no. 24, 2017,pp. 6148-615. 
[9] M. N. O. Sadiku, Y. Wang, S. Cui, S. M. Musa, "Precision agriculture: An introduction," International Journal of Advanced Engineering and Technology, vol. 2, no. 2, May 2018, , pp. 31-32.

[10] "4 Agriculture technology projects to transform the industry," http://ennomotive.com/agriculturetechnology-projects/

[11] "Agricultural drone," Wikipedia, the free encyclopedia, https://en.wikipedia.org/wiki/Agricultural_drone

[12] M. Aleksandrova "IoT in agriculture: Five technology uses for smart farming and challenges to consider," June 2018, https://dzone.com/articles/iot-in-agriculture-fivetechnology-uses-for-smart

[13] M. N. O. Sadiku, C. M. M. Kotteti, and S. M. Musa, "Machine learning in agriculture," International Journals of Advanced Research in Computer Science and Software Engineering, vol. 8, no. 6, June 2018, pp. 26-28.

[14] M. N. O. Sadiku, S. Cui, Y. Wang, S. M. Musa, "Big data in agriculture," International Journal of Advanced Research in Computer Science and Software Engineering, vol. 9, no. 4, pp. 70-72, April 2019.

[15] M. N. O. Sadiku, Y. Wang, S. Cui, and S. M. Musa, "A primer on blockchain," International Journal of Advances in Scientific Research and Engineering, vol. 4, no. 2, February 2018, pp. 40-44.

[16] "Pros and cons of agriculture technology," October 2019,

https://honestproscons.com/pros-and-cons-ofagriculture-technology/

[17] "What are the advantages and disadvantages of technology in agriculture?"

https://www.quora.com/What-are-the-

advantages-and-disadvantages-of-technology-inagriculture

[18] "24 Advantages and disadvantages of technology in agriculture," June 2019,

https://www.1001artificialplants.com/2019/06/0 6/24-advantages-and-disadvantages-oftechnology-in-agriculture/

[19]A. Yahya, Emerging Technologies in Agriculture, Livestock, and Climate. Springer, 2020.

[20] National Research Council, Emerging. Washington, DC: The National Academies Press, 2009.

[21] B. Subramanian, S. S. Chen, and K. R. Reddy (eds.), Emerging Technologies for Agriculture and Environment. Springer 2019.

[22] P. Ahmad and S. Rasool, Emerging Technologies and Management of Crop Stress Tolerance. Academic Press, 2014.

[23] T. Yamano, K. Otsuka, and F.

Place, Emerging Development of Agriculture in East Africa: Markets, Soil, and Innovations. Springer, 2011.

[24] E. F. Einsiedel,(ed.), Emerging Technologies: From Hindsight to Foresight.

[25] Toronto, Canada: UBC Press, 2009.

A. Rakshit (ed.), Emerging Innovations in Agriculture: From Theory to Practice. Athens, Greece: Athens Institute for Education and Research. 2015

[26] M. R. Goyal (ed.), Emerging Technologies in Agricultural Engineering. Apple Academic Press, 2017.

\section{AUTHORS}

Matthew N.O. Sadiku is a professor emeritus in the Department of Electrical and Computer Engineering at Prairie View A\&M University, Prairie View, Texas. He is the author of several books and papers. His areas of research interests include computational electromagnetics and computer networks. He is a fellow of IEEE.

Tolulope J. Ashaolu works at Southwest University, Chongqing, China. He is the author of several papers and books. His research interests include functional foods and food microbiology.

Sarhan M. Musa is a professor in the Department of Electrical and Computer Engineering at Prairie View A\&M University, Prairie View, Texas. He has been the director of Prairie View Networking Academy, Texas, since 2004. He is an LTD Sprint and Boeing Welliver Fellow. His areas of research interests include computational electromagnetics and computer networks.

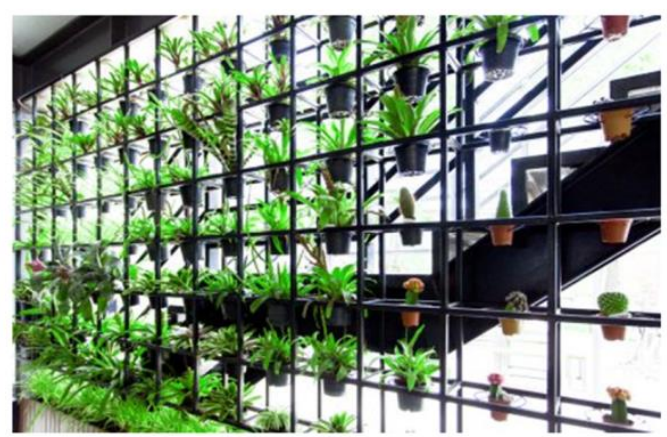

FIGURE 1: A TYPICAL VERTICAL FARMING [6].

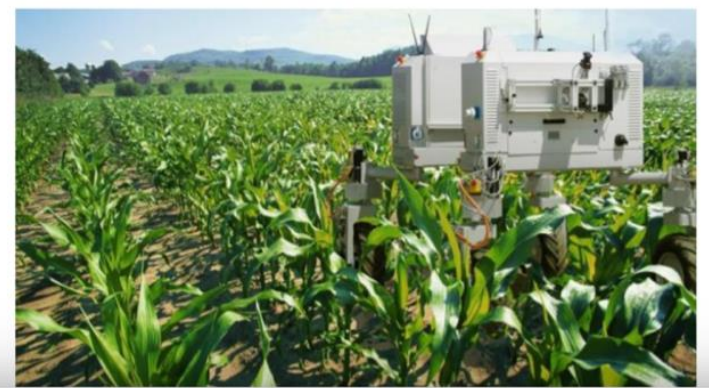

FIGURE 2: USE OF ROBOTS IN AGRICULTURE [10].

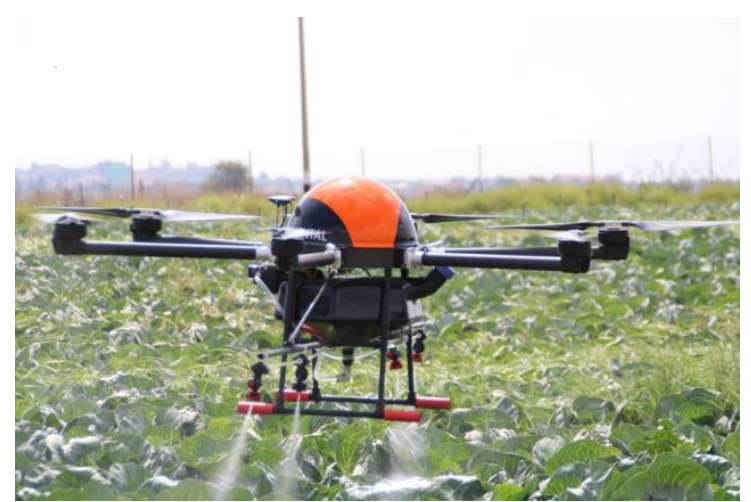

FIGURE 3: AN AGRICULTURAL DRONE [11].

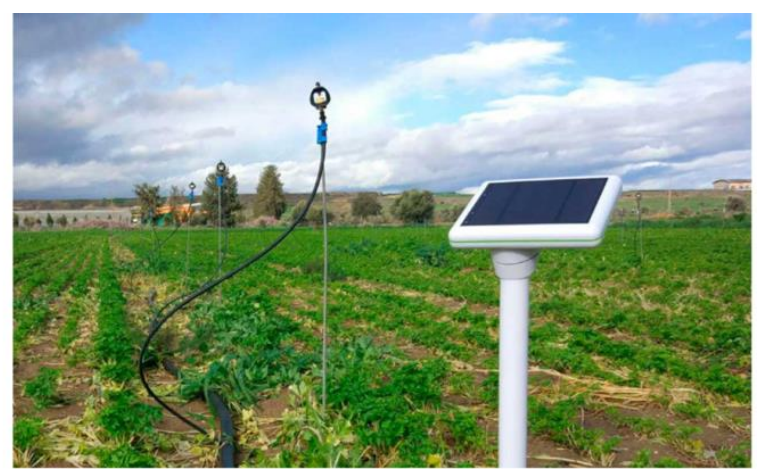

FIGURE 4: GREENHOUSE AUTOMATION [12]. 